\title{
Comparative ferrokinetic study with initial and extended iron clearance models
}

\author{
J E Howarth, H M Waters, K Hyde, D Shanks, C G Geary
}

\begin{abstract}
Erythrokinetic studies were performed on 10 patients with chronic myelofibrosis and 11 patients with myelodysplasia (MDS). Values for plasma iron turnover, marrow iron turnover, and erythron transferrin uptake were derived using two ferrokinetic models. One entailed analysis of the extended plasma iron clearance over a number of days, the other comprised analysis of the initial plasma iron clearance during the first few hours of the study. A close correlation was found between the variables quantifying total erythropoiesis (marrow iron turnover and erythron transferrin uptake) in the two methodologies. Functional classifications produced by both models and based on the values for plasma iron turnover, marrow iron turnover, and erythron transferrin uptake were compared. Both models identified functional heterogeneity in the group with myelofibrosis and functional homogeneity within the MDS group.

Each method produced comparable data on erythropoiesis. The main reason for analysing the extended plasma iron clearance is to differentiate levels of effective and ineffective erythropoiesis. The short analysis presents the practical advantages associated with a one-day study. This could be further enhanced if the level of effective erythropoiesis could be clearly defined.
\end{abstract}

The use of ferrokinetic studies to quantify erythropoiesis during haematological investigations has not been widely applied. While traditional measurements are relatively simple to perform, the variables which are derivednamely, plasma iron clearance, plasma iron turnover, and red cell utilisation, provide only limited information on the efficiency of total haemopoietic tissue in the production of mature, viable red cells. ${ }^{1}$

The introduction of a mathematical model for analysis of plasma iron clearance over 14 days has yielded clinically significant data. ${ }^{2}$ Erythropoietic activity is reflected by the marrow iron turnover, quantifying total erythropoiesis; red cell iron turnover, quantifying effective erythropoiesis; and ineffective iron turnover, quantifying ineffective erythropoiesis. Application of this methodology has also been limited as it is labour intensive, may require admission to hospital, entails the use of sophisticated computing facilities, and requires specialist interpretation.

An alternative approach, comprising a one day study, and calculation of erythron transferrin uptake as a measure of total erythropoiesis has been advocated. ${ }^{3}$ This is based on the fact that an important element in erythroid iron uptake is the degree of saturation of circulating transferrin. Transferrin receptors on developing erythroblasts have a far higher affinity for diferric than for monoferric transferrin. An approach which does not take this into account may produce a false estimate of the size of the erythron, and precise separation of erythroid activity into effective and ineffective components from simple analysis of the extended plasma iron clearance line may therefore be invalid. ${ }^{3}$

We analysed data derived from both models for the same patients to assess the comparability of the results obtained. Ten cases of chronic myelofibrosis and 11 cases of myelodysplasia (MDS) were studied in this way.

\section{Methods}

Ferrokinetic studies were performed on 21 patients referred for evaluation of haemopoiesis. Ten patients (cases 1 to 10 ) were diagnosed as having myelofibrosis according to clinical, morphological, and histological criteria. All presented with varying degrees of splenomegaly and increased bone marrow reticulin concentrations. For one patient (case 7), data before and after splenectomy are shown. Ferrokinetic data derived for these 10 patients from the extended plasma iron clearance line have already been published. ${ }^{4}$ Eleven patients (cases 11 to 21 ) were diagnosed as having MDS. All showed peripheral blood cytopenia combined with a cellular bone marrow, and were categorised according to the FAB classification. ${ }^{5}$ Three patients (cases 11,12 , and 13) were classified as having refractory anaemia ( $R A)$, three (cases 14,15 , and 16) as idiopathic sideroblastic anaemia (ISA), four (cases 17, 18, 19 and 20) as refractory anaemia with excess blasts (RAEB), and one (case 21) as RAEB in transformation (RAEB-t). Nine patients (cases 6, 7, 9, 10, 13, $15,16,18$ and 21) were transfused as required, excluding a period 10 days before or during the ferrokinetic study.

Transferrin and red cells were labelled with $0.185-0.37 \mathrm{MBq}{ }^{59} \mathrm{Fe}$ and $1.85 \mathrm{MBq}{ }^{51} \mathrm{Cr}$, respectively. ${ }^{67}$ The labelled samples were 
administered with a butterfly needle. The red cells were injected first, followed by the plasma. When half the plasma had been administered, the exact time was noted and collection of subsamples was timed from this moment. Anticoagulated samples $(10 \mathrm{ml})$ were taken at about 15, 45 and 75 minutes, and two and three hours after reinjection on the first day of the study (day 0 ). Further samples were then taken at timed intervals over 14 days. The exact time at which each specimen was taken was noted.

Red cell volume (RCV) was determined for each patient according to the method recommended by the International Committee for Standardization in Haematology. ${ }^{7}$ Plasma volume (PV) was measured by dilution of ${ }^{59} \mathrm{Fe}$ labelled transferrin within the plasma compartment. $^{8}$

Plasma iron clearance was analysed over an initial three hour period following injection of ${ }^{59} \mathrm{Fe}$-labelled transferrin, and the plasma iron clearance, plasma iron turnover and erythron transferrin uptake calculated. ${ }^{3}$ The extended iron clearance line was fitted to the sum of three exponential terms. ${ }^{2}$ In accordance with this method, corrections were made for serum iron fluctuations during this period and the plasma iron turnover and marrow iron turnover calculated. $^{2}$

Correlation studies were performed to determine the correlation between variables quantifying levels of total erythropoiesis (marrow iron turnover and erythron transferrin uptake) for patients with myelofibrosis and MDS. To test the ability of both models to produce a functional classification of bone marrow failure, agglomerative hierarchical cluster analysis ${ }^{9}$ was applied to delineate levels of homogeneity and heterogeneity within the two groups. Selected variables for this technique were those providing information on the rates of plasma iron turnover and total erythropoiesis. For the initial plasma iron clearance, these were plasma iron turnover and erythron transferrin uptake, respectively; for the extended plasma iron clearance, these were plasma iron turnover and marrow iron turnover, respectively.

\section{Results}

Haematological data for both groups of patients are shown in table 1. Most patients presented with anaemia of varying severity (mean haemoglobin concentration for myelofibrosis $=10 \cdot 1 \mathrm{~g} / \mathrm{dl}$, range 5.3 to $16 \mathrm{~g} / \mathrm{dl}$; mean haemoglobin for $\mathrm{MDS}=9.3 \mathrm{~g} / \mathrm{dl}$, range $7 \cdot 4$ to $10 \cdot 5 \mathrm{~g} / \mathrm{dl}$ ). The serum iron concentration and the initial and extended plasma iron clearance analyses for both groups are shown in tables 2 and 3, respectively. Results for marrow iron turnover and erythron transferrin uptake were analysed and compared. For the myelofibrosis group, marrow iron turnover was increased with the exception of cases $7 \mathrm{~b}, 9$, and 10. Erythron transferrin uptake was normal or increased, the lowest values again being shown by cases $7 b, 9$, and 10 . For the MDS group, marrow iron turnover was normal or increased with the exception of case 15 . The erythron transferrin uptake was also normal or increased, the lowest value again being shown by case 15.

Correlation studies showed a close association between erythron transferrin uptake and marrow iron turnover for both groups (correlation coefficient $=0.93$ and 0.80 , respectively).

The results for the cluster analysis are shown in table 4. For the initial plasma iron clearance data, four cases of myelofibrosis (cases 1, 4, 6 and 8 ) were assigned to cluster $A$, characterised by increased values for both erythron trans-

Table 1 Haematological data

\begin{tabular}{|c|c|c|c|c|c|c|c|c|c|}
\hline Case No & Sex & $W C C\left(10^{9} / l\right)$ & $R B C\left(10^{12} / l\right)$ & $H b(g / l)$ & $M C V(f l)$ & Plts $\left(10^{9} / l\right)$ & $R C V(l)$ & $P V(l)$ & $W B V(l)$ \\
\hline $\begin{array}{l}\text { Myelofibrosis: } \\
1 \\
2 \\
3 \\
4 \\
5 \\
6+ \\
7 \mathrm{a}+ \\
7 \mathrm{~b}+ \\
8 \\
9+ \\
10+\end{array}$ & $\begin{array}{l}\mathbf{F} \\
\mathbf{M} \\
\mathbf{M} \\
\mathbf{F} \\
\mathbf{M} \\
\mathbf{F} \\
\mathbf{M} \\
\mathbf{M} \\
\mathbf{M} \\
\mathbf{F} \\
\mathbf{F}\end{array}$ & $\begin{array}{r}7 \cdot 2 \\
4 \cdot 8 \\
18 \cdot 3 \\
7 \cdot 1 \\
14 \cdot 7 \\
2 \cdot 8 \\
5 \cdot 2 \\
12 \cdot 9 \\
8 \cdot 7 \\
6 \cdot 5 \\
1 \cdot 2\end{array}$ & $\begin{array}{l}6 \cdot 11 \\
5.46 \\
5 \cdot 12 \\
3.74 \\
4.02 \\
1.98 \\
3.13 \\
3.34 \\
3 \cdot 11 \\
2.04 \\
1.62\end{array}$ & $\begin{array}{r}16 \cdot 0 \\
14 \cdot 2 \\
12 \cdot 7 \\
10 \cdot 3 \\
10 \cdot 6 \\
6 \cdot 8 \\
9 \cdot 8 \\
10 \cdot 2 \\
9 \cdot 3 \\
6 \cdot 3 \\
5 \cdot 3\end{array}$ & $\begin{array}{r}83 \\
81 \\
76 \\
85 \\
76 \\
101 \\
86 \\
92 \\
87 \\
90 \\
88\end{array}$ & $\begin{array}{r}86 \\
185 \\
237 \\
119 \\
261 \\
176 \\
226 \\
246 \\
495 \\
263 \\
189\end{array}$ & $\begin{array}{l}2 \cdot 8 \\
2.8 \\
2 \cdot 1 \\
1.3 \\
1.3 \\
1.2 \\
1 \cdot 1 \\
1 \cdot 2 \\
1.3 \\
0.9 \\
1 \cdot 1\end{array}$ & $\begin{array}{l}3 \cdot 3 \\
4 \cdot 9 \\
4 \cdot 1 \\
3 \cdot 5 \\
3 \cdot 8 \\
4 \cdot 7 \\
3 \cdot 5 \\
3 \cdot 0 \\
5 \cdot 1 \\
3 \cdot 2 \\
3 \cdot 4\end{array}$ & $\begin{array}{l}6 \cdot 1 \\
7 \cdot 7 \\
6 \cdot 2 \\
4 \cdot 8 \\
5 \cdot 1 \\
5 \cdot 9 \\
4 \cdot 6 \\
4 \cdot 2 \\
6 \cdot 4 \\
4 \cdot 1 \\
4 \cdot 5\end{array}$ \\
\hline $\begin{array}{l}\text { Myelodysplasia: } \\
11 \\
12 \\
13+ \\
14 \\
15+ \\
16+ \\
17 \\
18+ \\
19 \\
20 \\
21+\end{array}$ & $\begin{array}{l}\mathbf{F} \\
\mathbf{F} \\
\mathbf{F} \\
\mathbf{F} \\
\mathbf{M} \\
\mathbf{F} \\
\mathbf{M} \\
\mathbf{F} \\
\mathbf{M} \\
\mathbf{M} \\
\mathbf{M}\end{array}$ & $\begin{array}{l}3.4 \\
4 \cdot 4 \\
2.9 \\
4.0 \\
1.9 \\
2.8 \\
2.5 \\
3 \cdot 4 \\
1.7 \\
5 \cdot 2 \\
2.0\end{array}$ & $\begin{array}{l}2.94 \\
2.76 \\
1.95 \\
3.06 \\
2.81 \\
2.67 \\
2.94 \\
2.59 \\
2.68 \\
4.34 \\
2.93\end{array}$ & $\begin{array}{r}9.5 \\
10.5 \\
7.4 \\
10.3 \\
8.9 \\
9.9 \\
9.8 \\
9.8 \\
8.9 \\
9.4 \\
9.4\end{array}$ & $\begin{array}{r}95 \\
116 \\
111 \\
104 \\
88 \\
92 \\
101 \\
113 \\
110 \\
68 \\
92\end{array}$ & $\begin{array}{r}255 \\
30 \\
10 \\
164 \\
36 \\
110 \\
167 \\
218 \\
58 \\
107 \\
37\end{array}$ & $\begin{array}{l}0.8 \\
1.0 \\
0.8 \\
0.8 \\
1.0 \\
0.9 \\
1.1 \\
1.1 \\
1.3 \\
1.5 \\
1.5\end{array}$ & $\begin{array}{l}2.9 \\
2.8 \\
2.7 \\
2.4 \\
3.5 \\
3.2 \\
3 \cdot 2 \\
2.3 \\
3.8 \\
3.5 \\
2.5\end{array}$ & $\begin{array}{l}3 \cdot 7 \\
3 \cdot 8 \\
3 \cdot 5 \\
3 \cdot 2 \\
4.5 \\
4 \cdot 1 \\
4 \cdot 3 \\
3 \cdot 4 \\
5 \cdot 1 \\
5 \cdot 0 \\
4 \cdot 0\end{array}$ \\
\hline $\begin{array}{l}\text { + Transfused be } \\
\text { Reference range } \\
\text { White cell count } \\
\text { Red cell count } \\
\text { Haemoglobin ( } \\
\text { Mean cell volum } \\
\text { Platelet count ( }\end{array}$ & 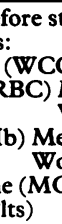 & 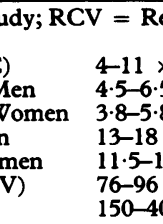 & $\begin{array}{l}\text { d cell volume; } \\
10^{9} / 1 \\
\times 10^{12} / 1 \\
\times 10^{12} / 1 \\
\mathrm{~g} / \mathrm{dl} \\
6.5 \mathrm{~g} / \mathrm{dl} \\
\mathrm{fl} \times 10^{9} / 1\end{array}$ & $=$ Pla & olume; V & - EThole & od volu & & \\
\hline
\end{tabular}


Table 2 Initial and extended iron clearance data for patients with myelofibrosis

\begin{tabular}{|c|c|c|c|c|c|c|c|c|}
\hline \multirow[b]{2}{*}{ Case No } & \multicolumn{3}{|c|}{ Iron concentration } & \multicolumn{3}{|c|}{ Initial clearance } & \multicolumn{2}{|c|}{ Extended clearance } \\
\hline & $\underset{(\mu \mathrm{mol})}{\operatorname{Serum} \mathrm{Fe}}$ & $T I B C$ & $\begin{array}{l}\text { Psat } \\
(\%)\end{array}$ & $\begin{array}{l}\text { PIC } \\
(\min )\end{array}$ & $\begin{array}{l}\text { PIT } \\
(\mu \mathrm{mol} / \mathrm{l} \text { blo }\end{array}$ & $\begin{array}{l}E T U \\
(24 h)\end{array}$ & $\begin{array}{l}P I T \\
(\mu \mathrm{mol} / \mathrm{l} b l\end{array}$ & $\begin{array}{r}M I T \\
(24 h)\end{array}$ \\
\hline $\begin{array}{c}1 \\
2 \\
3 \\
4 \\
5 \\
6+ \\
7 \mathrm{a}+ \\
7 \mathrm{~b}+ \\
8 \\
9+ \\
10+\end{array}$ & $\begin{array}{r}9 \cdot 0 \\
4 \cdot 1 \\
10 \cdot 8 \\
12 \cdot 0 \\
18 \cdot 0 \\
18 \cdot 3 \\
37 \cdot 0 \\
33 \cdot 0 \\
34 \cdot 0 \\
41 \cdot 7 \\
26 \cdot 0\end{array}$ & $\begin{array}{l}66.0 \\
73 \cdot 5 \\
42.0 \\
51.0 \\
49 \cdot 5 \\
44 \cdot 2 \\
40.5 \\
35.9 \\
34.5 \\
47 \cdot 7 \\
27 \cdot 0\end{array}$ & $\begin{array}{r}13.6 \\
5.6 \\
25 \cdot 7 \\
23.5 \\
36.4 \\
41 \cdot 4 \\
91 \cdot 4 \\
92.0 \\
98.6 \\
87 \cdot 4 \\
96.3\end{array}$ & $\begin{array}{r}12.5 \\
12.5 \\
25.0 \\
15.0 \\
38.0 \\
13.0 \\
74.0 \\
145.0 \\
27.0 \\
170.0 \\
135.0\end{array}$ & $\begin{array}{l}386 \\
102 \\
251 \\
395 \\
197 \\
643 \\
166 \\
183 \\
444 \\
170 \\
146\end{array}$ & $\begin{array}{r}292 \\
79 \\
159 \\
266 \\
190 \\
384 \\
64 \\
53 \\
203 \\
55 \\
48\end{array}$ & $\begin{array}{l}390 \\
187 \\
318 \\
550 \\
283 \\
507 \\
181 \\
163 \\
549 \\
155 \\
132\end{array}$ & $\begin{array}{r}388 \\
196 \\
310 \\
367 \\
195 \\
510 \\
173 \\
49 \\
412 \\
28 \\
24\end{array}$ \\
\hline Mean & $22 \cdot 2$ & $46 \cdot 5$ & $55 \cdot 4$ & $60 \cdot 6$ & 280 & 163 & 310 & 241 \\
\hline Range & $4 \cdot 1-41 \cdot 7$ & $27-73 \cdot 5$ & $5 \cdot 6-98 \cdot 6$ & $12 \cdot 5-170$ & $102-643$ & 43-384 & $132-550$ & $24-510$ \\
\hline
\end{tabular}

+ Transfused before study

Reference ranges:

Serum iron (Serum $\mathrm{Fe}$ )

Total iron binding capacity (TIBC)

Plasma iron clearance (PIC)

Plasma iron clearance (PIC)

Erythron transferrin uptake (ETU)

Marrow iron turnover (MIT)

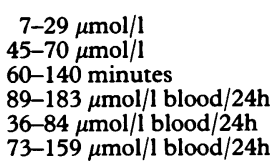

ferrin uptake and plasma iron turnover. The remaining cases (cases 2, 3, 5, 7, 9 and 10) were assigned to cluster $\mathrm{B}$, typified by lower levels for erythron transferrin uptake and plasma iron turnover. For the group with MDS, the results allocated one case only (case 14) to cluster A, the remainder being assigned to cluster $B$. For the extended plasma iron clearance data, five cases of myelofibrosis (cases $1,3,4,6$, and 8) were assigned to cluster $A$, characterised by increased values for both marrow iron turnover and plasma iron turnover. The remaining cases (cases 2, 5, 7, 9 and 10) were assigned to cluster $B$, typified by lower levels for marrow iron turnover and plasma iron turnover. For the group with MDS, one case only (case 14) was assigned to cluster $A$, the remainder being assigned to cluster $B$. With the exception of case 3, both ferrokinetic models were in agreement regarding the allocation of cases to cluster type.

\section{Discussion}

Myelofibrosis and MDS are complex haematological disorders. In both conditions evaluation of erythropoiesis by morphological analysis alone may prove difficult. Application of ferrokinetic studies results in both direct and objective quantitation, and provides valuable information regarding erythropoiesis.

The determination of plasma iron clearance, red cell utilisation, and plasma iron turnover alone is, at best, uninformative and, at worst, misleading. Mathematical analysis of the extended plasma iron clearance line ${ }^{2}$ provides meaningful data, but the procedure is timeconsuming, labour intensive, and presents problems regarding patient reattendance or admission. Analysis of the initial plasma iron clearance line ${ }^{3}$ produces information which, although less detailed, may be as informative in assessing erythropoiesis.

Data generated from 10 myelofibrosis and 11 MDS patients were analysed by both methods to rationalise the laboratory assessment of erythropoiesis. Some differences were obtained for the plasma iron turnover in the initial and extended clearance studies. This may reflect the fact that we adhered strictly to the respective methodologies, no corrections being made for serum iron fluctuation for the initial

Table 3 Initial and extended iron clearance data for patients with MDS

\begin{tabular}{|c|c|c|c|c|c|c|c|c|}
\hline \multirow[b]{2}{*}{ Case No } & \multicolumn{3}{|c|}{ Iron concentration } & \multicolumn{3}{|c|}{ Initial clearance } & \multicolumn{2}{|c|}{ Extended clearance } \\
\hline & \multicolumn{2}{|c|}{$\underset{(\mu \mathrm{mol} / l)}{\operatorname{Serum}} \underset{\mathrm{Fe}}{\mathrm{TIBC}}$} & \multirow[b]{2}{*}{$\begin{array}{l}\begin{array}{c}\text { Psat } \\
(\%)\end{array} \\
51 \cdot 7 \\
49 \cdot 9 \\
19 \cdot 0 \\
96 \cdot 4 \\
66 \cdot 7 \\
94 \cdot 2 \\
42 \cdot 0 \\
22 \cdot 0 \\
84 \cdot 7 \\
29 \cdot 3 \\
24 \cdot 2\end{array}$} & \multirow{2}{*}{$\begin{array}{l}\begin{array}{l}P I C \\
(\text { min })\end{array} \\
110 \\
100 \\
56 \\
52 \\
138 \\
85 \\
59 \\
79 \\
90 \\
61 \\
87\end{array}$} & \multicolumn{2}{|c|}{$\begin{array}{lr}P I T & E T U \\
(\mu \mathrm{mol} / \mathrm{l} \text { blood } / 24 \mathrm{~h})\end{array}$} & \multicolumn{2}{|c|}{$\begin{array}{lr}P I T & M I T \\
(\mu \mathrm{mol} / \mathrm{l} \text { blood } / 24 \mathrm{~h})\end{array}$} \\
\hline $\begin{array}{l}11 \\
12 \\
13+ \\
14 \\
15+ \\
16+ \\
17 \\
18+ \\
19 \\
20 \\
21+\end{array}$ & $\begin{array}{r}31 \cdot 0 \\
32 \cdot 2 \\
14.5 \\
28.5 \\
33 \cdot 0 \\
34 \cdot 2 \\
14.5 \\
13 \cdot 5 \\
30.5 \\
14.5 \\
8.0\end{array}$ & $\begin{array}{l}60 \cdot 0 \\
64.5 \\
76.5 \\
33 \cdot 0 \\
49 \cdot 5 \\
36 \cdot 3 \\
34.5 \\
61 \cdot 5 \\
36 \cdot 0 \\
49 \cdot 5 \\
33 \cdot 0\end{array}$ & & & $\begin{array}{l}232 \\
179 \\
174 \\
431 \\
145 \\
316 \\
126 \\
189 \\
161 \\
160 \\
198\end{array}$ & $\begin{array}{r}105 \\
80 \\
109 \\
193 \\
53 \\
129 \\
61 \\
111 \\
62 \\
87 \\
109\end{array}$ & $\begin{array}{l}210 \\
180 \\
212 \\
665 \\
185 \\
300 \\
187 \\
185 \\
164 \\
148 \\
170\end{array}$ & $\begin{array}{r}179 \\
153 \\
163 \\
380 \\
35 \\
82 \\
140 \\
183 \\
120 \\
132 \\
138\end{array}$ \\
\hline Mean & $23 \cdot 1$ & $48 \cdot 6$ & $52 \cdot 7$ & 83 & 210 & 100 & 237 & 155 \\
\hline Range & $8-34 \cdot 2$ & $33-76 \cdot 5$ & $19-96 \cdot 4$ & $52-138$ & $145-431$ & 53-193 & $148-665$ & $35-380$ \\
\hline \multicolumn{9}{|c|}{$\begin{array}{lc}\text { + Transfused before study } & \\
\text { Reference ranges: } & 7-29 \mu \mathrm{mol} / 1 \\
\text { Serum iron (Serum Fe) } & 45-70 \mu \mathrm{mol} / 1 \\
\text { Total iron binding capacity (TIBC) } & 60-140 \mathrm{minutes} \\
\text { Plasma iron clearance (PIC) } & 89-183 \mu \mathrm{mol} / 1 \mathrm{blood} / 24 \mathrm{~h} \\
\text { Plasma iron turnover (PIT) } & 36-84 \mu \mathrm{mol} / 1 \text { blood } / 24 \mathrm{~h} \\
\text { Erythron transferrin uptake (ETU) } & 73-159 \mu \mathrm{mol} / 1 \mathrm{blood} / 24 \mathrm{~h} \\
\text { Marrow iron turnover (MIT) } & \end{array}$} \\
\hline
\end{tabular}


Table 4 Cluster analysis

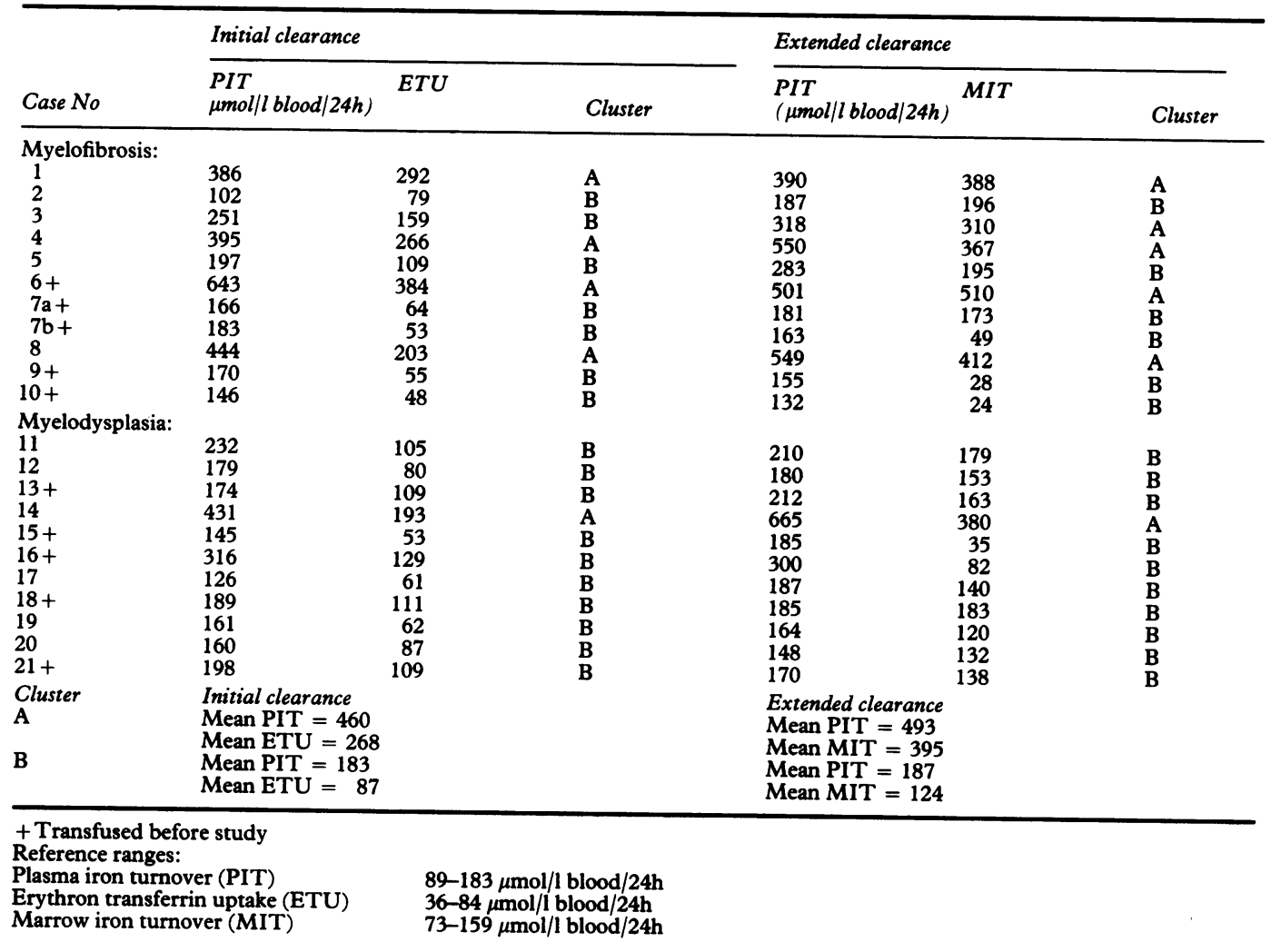

clearance studies, whereas corrections were applied for all samples in the extended studies. This resulted in slight changes in the respective line fits. There was, however, close correlation between the erythron transferrin uptake and marrow iron turnover which quantify total erythropoiesis in the two methods. The absolute values for erythron transferrin uptake and marrow iron turnover are not equivalent because the rationale of the two models differs. The extended plasma iron clearance model entails measurement of the ${ }^{59} \mathrm{Fe}$ reflux from macrophages to permit calculation of the level of ineffective erythropoiesis, and uses the plasma iron turnover and red cell utilisation figures to determine the level of effective erythropoiesis. In contrast, analysis of the initial plasma iron clearance line does not distinguish effective from ineffective erythropoiesis. Instead, this approach identifies the degree of iron saturation of circulating transferrin as a critical factor which has a major influence on erythroid iron uptake. This reflects the fact that erythroblast transferrin receptors possess a greater affinity for diferric than for monoferric transferrin. By contrast, the extended study assumes a single plasma iron pool with no consideration of the possible effect of transferrin saturation on iron turnover.

Cluster analysis identified two main clusters for each model. Analysis of the extended plasma iron clearance line ${ }^{2}$ defined one cluster comprising patients with high levels for both marrow iron turnover and plasma iron turnover, in contrast with the lower values for the second cluster. The group with myelofibrosis showed greater functional heterogeneity than the group with MDS. Results obtained from the initial plasma iron clearance line $^{3}$ also delineated two main clusters, one characterised by high levels for both erythron transferrin uptake and plasma iron turnover, in contrast with the lower levels observed in the second cluster. Again, the group with myelofibrosis showed greater heterogeneity than the group with MDS. Allocation of cases to cluster type by the two methods differed in only one case. Analysis of the initial plasma iron clearance line $^{3}$ assigned case 3 to cluster $B$ rather than to cluster A. This may be attributed to the difference in values obtained for plasma iron turnover as discussed above.

Application of both models has shown the functional heterogeneity within the 10 cases of myelofibrosis. This feature may not be apparent from morphological criteria alone. A previous study using ferrokinetic studies in combination with other variables identified two main prognostic groups for patients with myelofibrosis. ${ }^{10}$ Our clusters A and B displayed similar clinical characteristics to the two groups designated as low risk and high risk, respectively, in this earlier study.

The cases of MDS covered the morphological spectrum described by the FAB classification. ${ }^{5}$ In contrast, both ferrokinetic models emphasised functional homogeneity rather than heterogeneity of the group. Cluster analysis readily identified characteristics which differentiated one patient (case 14) from the other members of the group based on the increased values obtained for the plasma iron turnover, marrow iron turnover, and erythron transferrin uptake. Of the three cases morphologically classified as idiopathic sideroblas- 
tic anaemia, this patient alone did not have blast cells in the peripheral blood at the time of study.

Cazzola has identified three main clusters of MDS. ${ }^{11}$ All cases of RAEB and chronic myelomonocytic leukaemia (CMML) were allocated to one group, typified by marrow failure and an increased probability of developing acute leukaemia. The opposite end of the spectrum comprised patients with idiopathic sideroblastic anaemia who showed increased erythropoietic activity which was mainly ineffective. This group was reported to follow a benign clinical course with no evidence of leukaemic transformation. The erythropoietic activity of our case 14 was compatible with the latter group.

Further analysis of the functional characteristics of MDS suggest that ferrokinetic data seem to reflect the stage of the advancing leukaemic process. $^{12}$ Poor prognosis was characterised by low and ineffective erythroid activity. Decreased erythroid activity seemed to be closely related to blast cell numbers in the bone marrow and indicated progressive erythropoietic suppression associated with an increasing leukaemic cell mass. These observations suggest a more favourable prognosis for case 14 compared with the remaining cases of MDS. The progress of all the patients with MDS will be followed up to validate this hypothesis.

The main advantage of the extended plasma iron clearance model ${ }^{2}$ is its ability to detect levels of effective and ineffective erythropoiesis, although doubts have been expressed about the validity of these interpretations, particularly in patients with haemolytic disorders. ${ }^{1314}$ Nevertheless, our experience has been that a meticulous approach to the methodology produces clinically meaningful results. It is also possible to use the ferrokinetic data from this model to calculate the red cell lifespan. Careful attention must be given, however, to the erythropoietic activity of the patient because the success of this method depends on a steady rate of erythroid activity relative to the circulating red cell mass.

A one-day analysis of the initial plasma iron clearance line does not involve the use of sophisticated curve fitting procedures and can provide erythropoietic information which may not be readily apparent from cell morphology alone. ${ }^{3}$ Although our work has shown that both methodologies produce comparable data as regards levels of total erythropoiesis, the practical advantages provided by Cazzola's approach would be further enhanced if the proportion of the total erythron transferrin uptake directed to effective erythropoiesis was delineated. ${ }^{3}$ This may be possible by using the ${ }^{51} \mathrm{Cr}$ red cell lifespan measurement and the haemoglobin concentration to calculate the iron turnover directed to effective erythropoiesis. This could then be expressed as an "effective erythron transferrin uptake" by allowing for the transferrin saturation, thus enabling calculation of the fraction of the total erythron transferrin uptake directed to eifective erythropoiesis (Martin J Pippard, personal communication). Unfortunately, there may still be problems with interpretation because this calculation assumes that the percentage saturation of the total iron binding capacity remained constant throughout the two hour study period. Application of this method could theoretically provide valuable data regarding erythropoietic activity, but a 14 day study period would still be required for calculation of the ${ }^{51} \mathrm{Cr}$ red cell lifespan. Nevertheless, we consider that the potential for additional information justifies further investigation of this approach.

We are grateful to Dr I Cavill (Department of Haematology, University Hospital of Wales, Cardiff) for his help and advice, and for providing the methodology for the extended plasma iron
clearance studies. We also express our thanks to Professor M J Pippard (Department of Haematology, Ninewells Hospital and Medical School, Dundee) for his valued comments and suggestions.

1 Finch CA, Deubelbeiss K, Cook JD, et al. Ferrokinetics in man. Medicine (Baltimore) 1970;49:17-53.

2 Ricketts C, Jacobs A, Cavill I. Ferrokinetics and erythropoiesis in man: the measurement of effective erythropoiesis, ineffective erythropoiesis and red cell lifespan using ${ }^{59} \mathrm{Fe}$. Br J Haematol 1975;31:65-75.

3 Cazzola M, Huebers HA, Sayers MH, MacPhail AP, Eng M, Finch CA. Transferrin saturation, plasma iron turnover and transferrin uptake in normal humans. Blood 1985; 66:935-9.

4 Howarth JE, Waters HM, Hyde K, Geary CG. Detection of erythroid hypoplasia in myelofibrosis using erythrokinetic studies. J Clin Pathol 1989;42:1250-2.

5 Bennett JM, Catovsky D, Daniel MT, et al. Proposals for the classification of the myelodysplastic syndromes. $\mathrm{Br} \mathrm{J}$ Haematol 1982;51:189-99.

6 Cavill I. The preparation of ${ }^{59} \mathrm{Fe}$-labelled transferrin for ferrokinetic studies. J Clin Pathol 1971;24:472-4.

7 International Committee for Standardization in Haematology. Standard techniques for the measurement of red cell and plasma volume. Br J Haematol $1973 ; 25: 801-14$

8 Cavill I. Plasma clearance studies. In: Lewis SM, Bayly RJ, eds. Radionuclides in haematology. Edinburgh: Churchill Livingstone, 1986:214-44.

9 Everett B. Cluster analysis. London: Heinemann Educational Books, 1974:78-85.

10 Barosi G, Berzuini C, Liberato LN, Costa A, Polino G, Ascari E. A prognostic classification of myelofibrosis with myeloid metaplasia. Br J Haematol 1988;70:397-401.

11 Cazzola M, Barosi G, Berzuini C, et al. Quantitative evaluation of erythropoietic activity in dysmyelopoietic syn-

12 May SJ, Smith SA, Jacobs A, Williams A, Bailey-Wood A. The myelodysplastic syndrome: analysis of laboratory characteristics in relation to the FAB classification. $\mathrm{Br} J$ Haematol 1985;59:311-9.

13 Orr JS, Horton PW, Hutcheon AW, Dagg JH. Erythropoiesis and iron kinetics. Br J Haematol 1979, 42:155-64.

14 Bell R, Orr JS. Ferrokinetic analysis of clearance curves. Br J Haematol 1980;45:165-6. 